\title{
An Analysis of Confucius' Viewpoint of Morality by the Axiomatic Interpretation of the Analects
}

\author{
Xiao-Qing GAN ${ }^{1, a}$, Long-Yang SANG ${ }^{2, b},{ }^{*}$
}

${ }^{1}$ The Center of Cooperation \& Innovation for Lushan Culture of Jiujiang University 332005;

${ }^{2}$ Foreign Languages School of Jiujiang University 332005)

agxq2007@jju.edu.cn, ${ }^{\mathrm{b}}$ sangly@126.com

Keywords: The Analects, Axiomatic interpretation, Logical system, The viewpoint of morality, Confucius' thought.

\begin{abstract}
By reviewing the research history of the Analects, we expound the necessity and the possibility of the axiomatic interpretation of the Analects, and adopt an axiomatic approach to establish a deductive system built upon the fundamentals of the Analects. That is, after making some basic assumptions and giving some basic definitions, we formulate some axioms, and prove through deduction the series of propositions contained in the Analects by logical reasoning. In this way, the logical system of Confucius' thought implied in the Analects can be further brought to light.
\end{abstract}

As one of the most important Confucian classics, the Analects of Confucius embodies the essence of traditional Chinese culture. Over the past two thousand years, the thoughts and values it conveys that have profoundly influenced the moral concepts, behavioral logic and sensibilities of the Chinese people are at the core of traditional Chinese culture and thoughts. The influence of the Analects in the world is also great.

\section{The Necessity and Possibility of the Axiomatic Interpretation of the Analects}

By taking an overview of the research and transmission of the Analects at home and abroad, we can conclude that what is prevailing are the researches featured with the traditional Chinese exegetics and annotations, while those devoted to the reexamination of the Analects based on the modern academic methods and related disciplines are relatively rare.

How to objectively treat the Confucian classics represented by the Analects, and accurately evaluate their historical values and explore their modern significance is both a project that calls for serious study in the Chinese cultural circle and an unavoidable problem in Eastern and Western communication. However, in the eyes of the 18th-and-19th-century European philosophers, all Eastern philosophies are nothing but primitive religions without rational critical thinking, general thoughts rather than philosophies, as Hegel asserted: "Confucius is hence only a man who has a certain amount of practical and worldly wisdom--one with whom there is no speculative philosophy. In it, there is nothing definite further than a commonplace moral put in the form of good, sound doctrine."(Hegel, 1998:119-120) We believe that Hegel failed to do Confucius justice, missing the point in his criticism of the form and nature of China's Pre-Qin Philosophy.

Mr. You-Lan FENG resented his own observation of the value of Chinese philosophy in Western context according to his understanding of Chinese and Western philosophy. In the preface to the first volume of his A History of Chinese Philosophy, he points out that although no "formal systems" can be found in the works of Pre-Chin philosophers, yet in them there are "substantial systems" that await us to systemize. (You-Lan FENG, 1952:1-27)

When it only comes to the Analects, apparently, Confucius' teachings seem to lack close intrinsic connections, but Confucius has proclaimed that "all my teachings are linked together by one thread of ideas," which then can serve as an objective basis for people to interpret Confucius' teachings in a systematic way. However, the difference between Chinese and Western philosophy lies in that Western philosophy is systematic and speculative, centering around the relationship between 
thought and existence while in the center of the Chinese philosophy are basic propositions such as "internal saint and external king," "harmony between heaven and human beings" and "unity of knowledge and practice." By forming and expanding on these propositions, Chinese philosophers have established an equally systematic and speculative Eastern embodied philosophy. Therefore, if the cultural bias could be done away with, we would be able to adopt the axiomatic approach to deduce Confucian thought in the Analects and make systematic propositions as Spinoza does in The Ethics.

Our axiomatic interpretation of the Analects, at first, is to systemize the concepts and meanings employed in it and to work out their definitions according to their original meanings that are widely accepted by researchers of various generations and universally advocated by traditional Chinese culture, such as the benevolence, righteousness, rituals, wisdom, credit, filial piety, virtue, government and gentleman etc.. we take "ren" and "junzi" as examples:

Definition 1: By "ren", literally meaning "benevolence, "we refer to the state of mind and behaviour of a group of people who, starting with love based on consanguinity, can restrain themselves by learning, extend love to others and do everything according to rites, and therefore have developed the consideration (or forgiveness) of and respect for themselves, for others, for the society and the nature.

Definition 2: By "junzi", literally meaning "gentleman, man of honor, or superior man, "we refer to the person with a high status (a member of the governing class) acquired through the system of rites, sometimes, it also refers to the man of sound virtues.

Then, we propose some basic assumptions, definitions and axioms that correspond to the aforementioned definitions to deduce objective propositions that can reflect Confucian thought.

\section{The Basic Assumptions and Axioms}

We choose the 5 basic assumptions:

1.Everything is a unity of opposites of contradiction $G=\left(G^{\prime}, G^{\prime \prime}\right)$. Contradiction develops according to the law of reciprocal transformation of quantitative into qualitative changes and the law of the negation of the negation.

2.Suppose $M$ is the observer of $G$, it offers a pair of real numbers ( $\mathrm{d} G, \mathrm{~d} \mathrm{G}$ ") between $[0,1]$ in the development of $G$, where $d G^{\prime \prime}=1-d G$. We say that real number $d G$ ' is the "degree" of contradiction $\mathrm{G}$, which relies on the state of $\mathrm{G}$, time $\mathrm{T}$ and observer $\mathrm{M}$.

3. For contradiction $\mathrm{G}$, if there is a time period $(\mathrm{t} *, \mathrm{t} *+\mathrm{Nt})(\mathrm{N}$ is a sufficiently large natural number), it has the following properties: any two times $\mathrm{t}^{\prime}, \mathrm{t}^{\prime \prime}$ in this period and any two observers $\mathrm{M}^{\prime}$, M", except a very small number of people, are randomly selected; the value difference between the two degrees is very small, then we assert that contradiction $G$ has a "stable degree", and any state for contradiction $\mathrm{G}$ within this period is said to be "stable" or "mean" state.

4.Let $\mathrm{H}$ be the set for the adults of a certain community with labor division. Supposing the contradiction $\mathrm{C}=\left(\mathrm{C}^{\prime}\right.$ and $\mathrm{C}$ ") be "the basic motive of one's social behaviour" $\mathrm{P}$ in $\mathrm{H}, \mathrm{C}^{\prime}$ refers to the "naturality" (or "one's instinct") of motive, and C" refers to the "sociality" (or "interactivity").

5. For a certain individual $\mathrm{P}$, when the contradiction $\mathrm{C}(\mathrm{t}, \mathrm{P})$ for the above motive has its stable period and state (or the mean state), we say that this mean state is P's state of "righteousness."

If, among $\mathrm{H}$, except a very small number of people, the motive of contradiction $\mathrm{C}(\mathrm{t}, \mathrm{P})$ for allindividuals $\mathrm{P}$ has a common stable period, and the difference of degree for the contradiction $\mathrm{C}$ that any two different individuals $\mathrm{P}^{\prime}, \mathrm{P}$ " correspond to is also very small, the state of righteousness of any individual $\mathrm{P}$ among $\mathrm{H}$ is said to be in the "harmonious" state of the group $\mathrm{H}$ and is denoted as $\mathrm{C}(\mathrm{H})$.

Through social division of labor, the two different groups, the governing A and the governed B are formed in a community $\mathrm{H}$. If both $\mathrm{A}$ and $\mathrm{B}$ exist in a "harmonious" state, and the difference between $\mathrm{dC}(\mathrm{A})$ and $\mathrm{dC}(\mathrm{B})$ is small, the community $\mathrm{H}$ is said to be in a state in which the Way prevails.

We also choose the 5 Axioms: 
A1. Most people are not much different in their natural endowments. By making self-adjustment (self-cultivation) when faced with contradiction in their social behavior, they can approximate "righteousness."

A2. Self-adjustment to "righteousness" can bring pleasure.

A3. A man's value lies in the fact that he can assume his social duty on his own initiative according to the principles of benevolence and rites. His value is judged by the society according to the doctrine that "those who are good like him and those who are bad dislike him" as well as by his "conscience" based on benevolence.

A4. To practice benevolence is a gentlemanly behavior. Benevolence is conferred first to his kinsmen, and then to his neighbors, and by extension to all the humans and even Mother Nature.

A5. A gentleman, as the inheritor of tradition, assumes responsibility to enhance self-cultivation for the promotion of the society so that it approximates the Way.

\section{Some Propositions to Cultivate Virtue in the Confucianism and Their Proofs}

To pursue "Way" and cultivate virtue of gentlemen is the core of Confucianism. We mainly discusses the concrete ways of establishing the moral necessity in the contradictions in the motive of the "naturality" and "sociality" in people's "social behavior", that is , to prove the basic requirements and the connotation of the moral basis including "benevolence (ren)," "rites (li)," "music (yue)" and "learning (xue), and the moral categories including "filial piety (xiao)," "loyalty (zhong)," "trustworthiness (xin)," "righteousness (yi)" and "wisdom/knowledge/realization(zhi)". Cultivation of virtue reflects the virtuous characteristics in a gentleman's character and behaviour, namely, the basic norms of "knowing the decree of heaven," "being benevolent," "observing rites," "being trustworthy" and "observing filial piety" by gentlemen.

Proposition 1. The meanings of the "Way" and its realization depend on man's efforts.

See the Analects:

The Master said, "It is Man who is capable of broadening the Way. It is not the Way that is capable of broadening Man." (Book 15)

Proof: According to the basic assumption 5, "the prevalence of the Way" (youdao) is the outcome of man's adjustment of the motives in his conduct. If he adjusts them and extends them to set both the governing and the governed in a harmonious state, then we call it a society where the Way prevails. Therefore, the Way is a consensus derived from man's long-term social interaction and an intensive reflection of man's needs to live together under the restrictions of environment. Man comes to learn what "the prevalence of the Way" means and facilitates its gradual realization. During the pursuit of "the prevalence of the Way," many specific virtues emerge on the basis of "benevolence" and "rites." Therefore, the meanings of the "Way" and its realization depend on man's efforts.

Proposition 2. The "Way" is the objective of all virtues.

See the Analects:

The Master said, "Wealth and high station are what men desire, but unless I got them in the rightway I would not accept them. Poverty and low station are what men detest, but if I did not get rid of them in the right way, I would not try to take myself away from them."(Book 4)

Of Zichan the Master said that in him were to be found four of the virtues that belong to the Way of the true gentleman: he was respectful in the manner he conducted himself; he was reverent in the service of his lord; in attending to needs of the common people, he was generous and, in employing their services, he was appropriate. (Book 5)

Proof: According to A5, a gentleman, as the inheritor of tradition, assumes responsibility to enhance self-cultivation for the promotion of the society so that it approximates the Way. From the definition of "gentleman", it refers to the person with a high status acquired through the system of rites (a member of the governing class). Sometimes, a gentleman also refers to the man of sound virtues, for virtue is a general term of "rites" and "benevolence." A gentleman should try to promote his self-cultivation to make the whole society approximate "the prevalence of the Way". Therefore, the "Way" is the objective of all virtues. 
Proposition 3. To practice benevolence is the goal of a gentleman's life.

See the Analects:

The Master said, "Never for a moment should the gentleman desert benevolence. He clings to benevolence whether in moments of haste or in times of hardship." (Book 4)

Proof: According to A5, a gentleman's responsibility is to promote the society close to "the prevalence of the Way" by improving his self-cultivation. Further, a man's value lies in the fact that he can assume his social duty on his own initiative according to the principles of benevolence and rites (by A3). To a gentleman, therefore, the practice of benevolence is his goal of life.

Proposition 4. The practice of benevolence depends on oneself alone, and not on others.

See the Analects:

The Master said, "To practice self-discipline and to observe the rites constitute benevolence. If for a single day a man could return to the observance of the rites through overcoming himself, then the whole empire would consider him benevolent, defer to his model and would be in good order. The practice of benevolence depends on oneself alone, and not on others." Yan Yuan said, "I should like you to list the detailed items." The Master said, "Do not look unless it is in accordance with the rites; do not listen unless it is in accordance with the rites; do not speak unless it is in accordance with the rites; do not move unless it is in accordance with the rites." (Book 12)

Proof: From the definition of "benevolence", a benevolent man must be caring and restrain himself by rites, and he should be considerate of and show respect for others. Further, a man should assume his social duty on his own initiative according to the principles of benevolence and rites and his conscience is the judging criterion (by A3). All of these are personal feelings, not being imposed upon by objective conditions. Therefore, the practice of benevolence depends on oneself alone, and not on others."

Proposition 5. Loyalty and forgiveness are the fundamental ways to practice benevolence.

See the Analects:

Zigong asked, "Is there a single word which can be a guide to conduct throughout one's life?" The Master said, "It is perhaps the word 'forgiveness'. Do not impose on others what you yourself do not desire." (Book 15)

The Master said, "Shen! There is one single thread binding my way together." Master Zeng Shen(Zengzi) assented. After the Master had gone out, other disciples asked, "What did he mean?" Zengzi said, "The way of our Master can be simplified into loyalty and consideration. That is all." (Book 4)

Proof: Most people do not differ very much in their natural endowments (by A1). One can understand what others feel through empathy, which constitutes the basis for forgiveness, and loyalty means doing one's uttermost for others. So loyalty and forgiveness mean not only doing one's uttermost for others out of love but also putting oneself in others' shoes in this process so as to adjust his own behaviours, that is, to be loving, respectful to and considerate of others in practice. Therefore, Loyalty and forgiveness are the fundamental ways to practice benevolence.

Proposition 6. To practice self-discipline and to observe the rites constitute benevolence.

See the Analects:

The Master said, "To practice self-discipline and to observe the rites constitute benevolence." (Book 12)

Zizhang asked Confucius about benevolence. Confucius said, "One who can develop the five qualities and is capable of putting them into practice in the world is certainly 'benevolent'." "May I ask what they are?" "They are respectfulness, tolerance, trustworthiness in word, diligence and generosity. If a man is respectful, he will not be treated with insolence. If he is tolerant he will win the multitude. If he is trustworthy in word, his fellow men will trust him. If he is diligent, he will succeed in all he undertakes. If he is generous, he can get service from the people. (Book 17)

Proof: Man adjusts his motives to make them conform to the rites through learning and thinking when faced with contradictions in his social behaviour (by A1). From the definition of "benevolence", rites are the external representation of benevolence, which means one can restrain himself through learning and spread his love to others. And if people all over the world are in this 
mental state, the world will be full of benevolence. Therefore, to practice self-discipline and to observe the rites constitute benevolence.

\section{References}

[1] Hegel, Lectures on History of Philosophy, Vol.1, Beijing: the commercial Press, 1981: pp119-120(In Chinese)

[2] You-Lan FENG, A History of Chinese Philosophy, Vol.1, the Princeton University Press, 1952:PP1-27 